Article

\title{
Intelligent Transport System in Chile
}

\author{
Jorge Figueroa ${ }^{1}$, Raúl Carrasco ${ }^{2, *} \mathbb{C}$, Diego Fuentealba ${ }^{3,4}\left(\mathbb{D}\right.$, Eduardo Viera ${ }^{5}(\mathbb{D}$ and \\ Carolina Lagos ${ }^{6}$ (i)
}

1 Departamento de Industria, Universidad Tecnológica Metropolitana, Santiago 7800002, Chile; jfigueroa@utem.cl

2 Facultad de Ingeniería, Ciencia y Tecnología, Universidad Bernardo O’Higgins, Santiago 8370993, Chile; raul.carrasco.a@usach.cl

3 Escuela de Informática y Telecomunicaciones, Universidad Tecnologica de Chile- Inacap, Santiago 7650033, Chile

4 VirtuaLab, Depart of Industrial Engineering, Universidad de Santiago, Santiago 9170124, Chile; diego.fuentealbac@usach.cl

5 Departamento de Ingenieria Electrica, Universidad Santiago de Chile, Santiago 9170124, Chile; eduardo.vierar@usach.cl

6 Facultad de Ingeniería, Pontificia Universidad Católica de Valparaíso, Valparaíso 2362804, Chile; Carolina.lagos@pucv.cl

* Correspondence: raul.carrasco.a@usach.cl; (R.C.)

\begin{abstract}
Today, transit control systems go beyond simple controllers located at the intersections of our streets, involving large companies in the field, which with the implementation and use of sophisticated equipment encompass endless new and advanced technologies that manage to give control to the massive automotive park, thus ensuring fluidity and road safety. Many of these systems are used in the big world capitals, which is why the model used in Santiago, Chile is a system applied and brought directly by the SIEMENS Company of England (specifically the system used in the City of London). It is capable of transmitting the different control signals in a similar and digital way from the different interconnected devices in and out of the road infrastructure.
\end{abstract}

Keywords: Intelligent transport systems; SCOOT; traffic control; traffic light; UOCT

\section{Introduction}

Since the invention of the first vehicle, an uncontrolled massification of this instrument of land mobilization has been generated throughout history, and with this has also grown the need to be able to control and manage the roads through which they transit, in order to avoid accidents and congestion.

The term "Traffic Management" [1] refers to the process of adjusting or adapting the use of an existing network of streets to achieve specific objectives without resorting to changing the existing environment. In this way, the use of technologies capable of communicating the different traffic systems that are involved with each other, in order to improve the road space, will be related. It is necessary to clarify that this study only mentioned the technologies and applications used in the management and control of ground traffic.

Zaldivar-Colado et al. [2] propose the management of traffic lights in an emergency procedure for firefighters and ambulances, facilitating driving on the emergency route.

It shows the different technologies used today in the city of Santiago for the control and management of traffic. Mainly, we will focus on publicizing the programming and communication that exists between traffic lights and the equipment that controls them, which are able to integrate various procedures in order to generate a better use of the routes and thus facilitate the displacement of 
people [3]. In this attempt to control the vehicular flow are involved entities, both private and public, that interact with the objective of managing to manipulate, program, communicate and design the different parameters necessary to make constant the daily harmony of this city.

On the other hand, there is also a widely used application today for time planning at traffic lights, corresponding to the dynamic controls of traffic lights, which are called Split Cycle Offset Optimisation Technique (SCOOT) and Sydney Coordinated Adaptive Traffic System (SCATS), which use information from vehicle flows in the vicinity of traffic lights to determine the optimal schedules of the crossings [4].

The main thing to be able to understand this type of technology is to know how the communication scheme that exists between the teams that are located in the field with the control room equipment located in the Operational Traffic Control Unit (UOCT) is constituted, which is the entity in charge of transit management and planning, where operators have the possibility to manipulate, depending on the need, the programming of an " $\mathrm{X}$ " traffic light.

For this, we have implemented several devices located in the most conflicting junctions, able to deliver in real time the information necessary to be able to make the right decision when managing the vehicle flow.

In Figure 1 is a simplified field Communication Framework of a traffic light controller and a Closed Circuit Television (CCTv) camera with the systems in the UOCT.

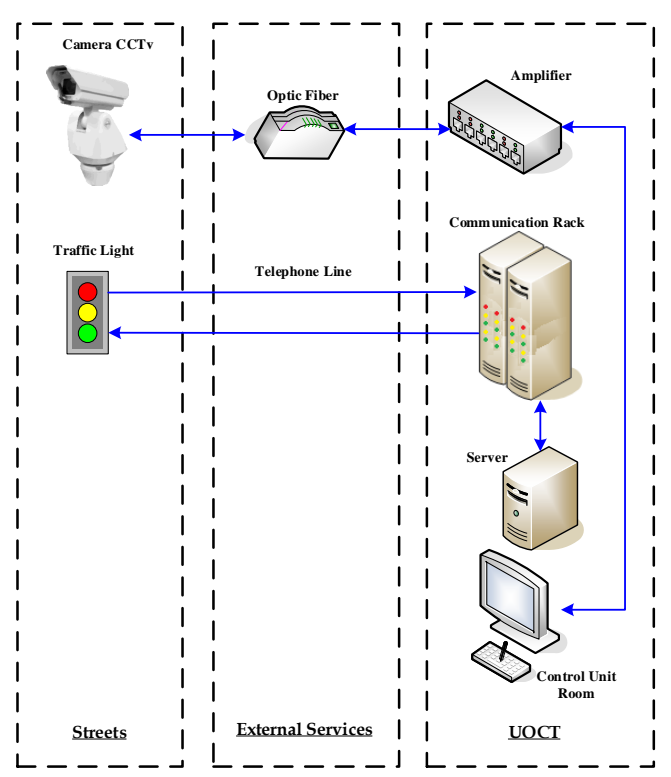

Figure 1. Communication Framework.

\section{Development}

What are Intelligent Transport Systems (ITS) and how do they make our lives easier? These are very essential and important questions to answer and as each of them is broken down, it will be seen how important they are and how necessary it is to implement them today in order to be able to control the automotive park that is growing exponentially.

ITS are transport systems in which groups of technologies created and used have been integrated for the sole purpose of informing and controlling road networks. This makes them more effective, dynamic and operable[5] with energy efficiency [6].

The most commonly accepted definition of ITS is "the application of computer, control and communications technologies to help drivers and operators make smart decisions while driving smart vehicles or controlling traffic on smart roads or-railroads" [7].

It should be said that for each technology group it is essential to carry out an intensive study of the needs that will be met in order to verify if they are feasible and that they will be in force for a long 
time. The means of transport arise as the first option of improvement of the quality of life and for this it is also effective to control and manage ITS partial or complete mobilization through the cities. Through the application of ITS, it is possible to know the changes that are made in real time in urban roads due to the alteration of the environment in which we mobilize. Therefore, we can act on these events and try to control them to minimize the impact they would have on the life of a city.

Some of the reasons why the importance of applying certain technologies to means of transport arises are:

- The need to have control over traffic.

- Managing the roads as best as possible due to population growth.

- Better communication.

- Urban settlement.

- Comfort and performance.

- Automating the field of transport.

This integration of new technologies at the service of greater efficiency, quality, safety and lower environmental impacts has been adopted in different institutions in our country, such as concession highways, state railways, Metro and perhaps the most important the UOCT [8].

\subsection{ITS segmentation}

Any system that uses information and control technologies that are integrated into ITS can be broken down into process sub-functions, collection and dissemination of relevant information, and in turn into the decision and control support based on the information collected [9]. In ITS, these sub-functions apply to traffic, vehicles and people involved in this need to improve interaction between them. These functions may be summarized in:

\section{Acquisition of data:}

In this grouping, you will discover every one of the capacities that has to do with the assortment of data. The fundamental necessity for this sub-work is that the gathered data must be exact and accessible at the time it is required.

Data transmission:

Information transmission is another key capacity in ITS administrations. There are two classifications of specialized methods for transmitting data: fixed terminals such as phone, radio and TV, and portable terminals such as mobile phones and radio. Regularly, they are additionally delegated wired and remote transmission.

Central control room:

Since data of an alternate sort is being gathered at the same time in different spots, a control focus is expected to combine and process all information. The control focus is the place in which administrators get the information and, bolstered by devices, such as programming and equipment, they settle on choices about the vehicle framework.

Vehicle:

There are three fundamental sorts of sensors in vehicles: those that record the outright position, those that record the relative position and those that record the activity of the vehicle. Then again, there are interfaces between the framework and the driver, which are additionally situated in the vehicle and range from radios to complex route frameworks. Finally, in the vehicle there are additional control gadgets, which permit the vehicle to work from the control fixation or work itself on the data that it can gather from the framework. 


\subsection{Application of ITS in Chile}

An early application of ITS and already time tested corresponds to the dynamic controls of traffic lights. These are called SCOOT and SCATS, which use the information of the vehicle flows in the vicinity of the traffic lights to determine the optimal schedules of each [10].

Intelligent crossover control, as defined, automatically manages to reduce the speed of vehicles in order to maintain a safe interval with the vehicle that precedes it. This is clearly an example of the technology developed and implemented at Santiago's most conflicted crossings. Another application is the dynamic route guides, which recommend to the driver the optimal route to take for a given destination taking into account the current and projected conditions of the roads and traffic. This system is also known as Global Positioning System (GPS), whose technology is based to take as much data as to transform it into positional information.

A second group of ITS applications is observed as part of the development of road works concessions. In this case, the applications mainly refer to the registration and control of payment of tolls, electronic toll payment systems and emergency services to the user. In the case of tolls, such systems exist in operation on the Autopista del Sol and access to The Airport A. Merino Benítez de Santiago, and in the short term this system should start operating on the Santiago - Talca Highway, and then on the rest of the toll road concessions. With the start of urban road concessions, a major development of ITS applications in previous aerial applications as well as in user information services is expected.

This is mainly explained by the requirement of tolls as a method of collection in urban concessions (Oriente- Westeros System, North-South System and Américo Vespucio), which must also be interoperable between the different concessions, thus defining a standard of communications between the transponder (TAG) of the vehicle and the access portico. However, these concessions also consist of incident detection systems in the tunnels, emergency services and variable message panels to inform the user, which makes it necessary to establish traffic control and road safety systems for each highway.

There is also a strong interest on the part of the Road Management to incorporate state-of-the-art technologies into road management, in particular at border crossings, information collection, maintenance management and others.

In the private sector, some ITS applications are also seen, mainly in income control and parking control, although fleet control applications and reduced business formalities are expected to be incorporated in the transport of Load.

Some systems that are currently operating are summarized in Table 1, shown below:

Table 1. ITS in Chile in operation.

\begin{tabular}{|c|c|c|c|}
\hline & Project & Operator & Description \\
\hline 1 & $\begin{array}{l}\text { Santiago Traffic Control } \\
\text { System }\end{array}$ & $\begin{array}{l}\text { Operations Traffic } \\
\text { Control Unit }\end{array}$ & $\begin{array}{ll}\text { - } & \text { Control of } 2450 \text { intersections } 960 \text { Intersections } \\
& \text { with SCOOT dynamic control } \\
\text { - } & \text { 80 CCTv Cameras } \\
\text { Geographic Information System (GIS) } & \text { 8 Variable message signs } \\
\text { - } \quad \text { W0 Networked vehicle counters } & \text { Website of traffic information to users }\end{array}$ \\
\hline 2 & $\begin{array}{l}\text { Great Valparaiso Traffic } \\
\text { Control System }\end{array}$ & SECTRA & $\begin{array}{ll}\text { - } & \text { Controlling } 100 \text { intersections } \\
\text { Fixed time control } & \text { 27CCTv monitoring cameras } \\
\text { - } & \text { Vehicle counters } \\
& \text { Traffic information website to users }\end{array}$ \\
\hline 3 & $\begin{array}{l}\text { Operations, Monitoring } \\
\text { and Control System }\end{array}$ & $\begin{array}{l}\text { Metro de Santiago } \\
\text { and Transantiago }\end{array}$ & $\begin{array}{ll}\text { - } & \text { Fleet monitoring and control system } \\
\text { Tracking and locating trains and buses } \\
\text { - } & \text { Frequency control } \\
\text { Dispatch system }\end{array}$ \\
\hline
\end{tabular}




\subsection{Traffic lights}

The main function of a traffic light in the control of an intersection is to give way to different groups of vehicles (and pedestrians), so that they circulate through the intersection with a minimum of problems, risks and delays. The design objectives of a traffic light-controlled intersection can be summarized in four key points:

- $\quad$ Reduce and prevent accidents at the intersection and their immediate proximity.

- Reduce delays faced by pedestrians and vehicles when crossing the intersection, including avoiding the blocking of crossings by long queues.

- Reduce fuel consumption at the intersection.

- $\quad$ Reduce the emission of air pollutants and other factors that deteriorate the environment

2.4. Types of traffic lights

Currently you can distinguish 4 different types of traffic lights. These are:

1. Fixed scheduled time semaphore, in which the sequence of phases presented to transit changes according to a fixed program specified externally by the designer. A traffic light can have several programs, which are activated at different times of the day to better adapt to demand [11].

2. Traffic-regulated or traffic-activated traffic lights, in which the duration of each phase and sometimes ITS order depends on the very transit that the intersection uses. This demand is identified by detectors (pneumatics, induction loops, etc.). Basic logic is also specified by the designer.

3. Set of interconnected and coordinated traffic lights. In this case, the programs of each traffic light are established in advance by the designer, who also establishes how they will obey a central control.

4. Combinations of these types such as coordinated systems that can also respond to instant demand. The colors to use in a traffic light are red, yellow and green. They are defined in NCh 1437 -111-79 of the National Institute of Standardization [12].

\subsection{Communication system}

The Santiago Transit Control System is a centralized system that allows remote coordination, monitoring and monitoring of the operation of almost all existing traffic lights in the city. It operates permanently in real time, transmitting second by second instructions to each of the traffic lights, and in turn, receiving different information from each traffic light controller such as the level of congestion, data recorded by the coils located in conflict zones, state of lights and vehicular flow. It is through this system that the management of the traffic lights of the city is carried out and that exceeds the 2,400 intersections [13].

\subsection{Transit Control System Interface}

The transit control system of the city of Santiago is very complex because of the large amount of data it handles, whether it is control, monitoring or coordination of the crossings. Therefore, as it should operate in real time, it is necessary to use an executable software on Windows platform called "XVision" [15], which is installed on the Traffic Control Centre (TCC) servers and on the Central Traffic Management Computer (TMC) server. Through it, you will be able to access the different information of the control system. The system works on two types of modality.

Pre-set time plans:

In this mode it operates eighty-five percent of all traffic lights. It consists of the implementation of predefined traffic light time schedules in specialized studies that are entered in a time table of the transit control system, which activates at the traffic lights those schedules in hours and days specifics. 


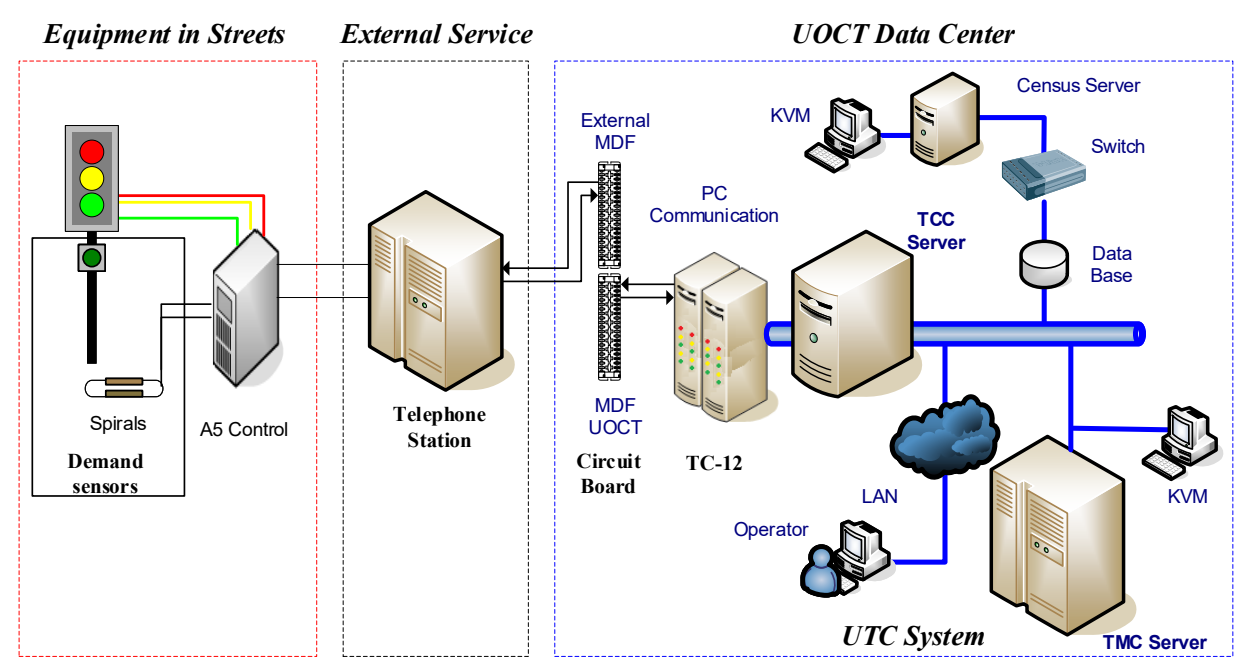

Figure 2. Scheme Control Systems, based on Siemens AG [14].

Dynamic control or SCOOT:

Currently, only fifteen percent of traffic lights operate in this mode. They are also called smart traffic lights as they use sensors installed on the road. The traffic control system collects information about the vehicle flow through these sensors and thus elaborates traffic light time schedules, optimizing traffic lights, which it then implements at the respective traffic lights.

When the software works in SCOOTD mode [16,17], the vehicular flow of a junction that is working in that mode can be monitored through the command application. However, when junctions work in default plan mode, it is possible to check the status of the Outstation Transmission Unit (OTU), the execution of plans, time table, scheduling of junctions, etc. Furthermore, and most importantly, is that you can make changes from plans in real time to crossings that are conflicting in peak hours.

All this is done from the positions of the operators that fulfill the function of a terminal. These are located in the control room, which are connected through the network to receive and send information to the central server.

\section{TCC, TMC and Communications PC:}

Servers are identified in the control system with the letter $\mathrm{H}$ and six digits. This nomenclature is required in order to be able to verify the status of the TCC and TMC servers [18].

Table 2. OCT Servers [19].

\begin{tabular}{llc}
\hline Server & Area of operation & Nomenclature \\
\hline TCCA & Scoot east & H001000 \\
TCCB & Fixed time east & H002000 \\
TCCC & Fixed time west & H003000 \\
TCCD & Scoot west & H004000 \\
TCCE & Fixed weather east 2 & H005000 \\
TCCF & Fixed time west 2 & H006000 \\
TMC & Data server & H099000 \\
\hline
\end{tabular}

Network:

Grouping of traffic lights according to their location, periodization and optimal operating cycles.

- Networks operating at set times (fixed times or semi-acting): Implementation of predefined schedules, obtained from historical counts of vehicle flows. The preset time plans are entered into a timetable of the transit control system that activates them on specific times and days. 
- Networks operating under dynamic control (SCOOT): So-called smart traffic lights, as traffic light times are permanently adapted to existing demand. This demand is captured through sensors installed under the roadway in each of the network arches.

- Isolated traffic lights (full-acting): They are usually located on the periphery of the city. They are devices isolated especially so they do not require coordination with other traffic lights. In them, there are sensors located in each of ITS accesses and the rights of passage are granted according to the specific demand that exists.

On the system, the nomenclature of a network is Axxx000, with $x x x$ being the assigned network number, this being applicable for the other system objects.

\subsection{Vehicle Detection}

Inductive-loop traffic detectors:

There are currently a variety of forms used for vehicle detection, from closed-circuit cameras, RF receivers to simple cable inductive-loops. All are used in order to monitor the traffic produced at the intersection.

The Inductive-loop traffic detectors, as mentioned above, is an element that helps in the detection of the passage of vehicles through a certain road by collecting information about the flow that is currently occurring. The advantage of this system is to work on the basis of the information that is delivered in real time. These act as sensors when the control system enters SCOOT mode [20].

The coil basically consists of two copper wires that are braided and installed at a significant distance from the stop point of the intersection that is required to be monitored. This should be securely fastened on the roadway to avoid displacement and vibration which could lead to increases in frequency and would result in interpretations of fake vehicles. This inductive loop is used in various applications such as for protection, vehicle separation or to detect the presence of vehicles. In the first two cases, it is used for access control or weighing and in the third, it is used for dynamic control called SCOOT, which consists of intelligent algorithms that are in line with the control system.

The return of the inductive-loop is made with the same thread, whose maximum length reaches $300 \mathrm{~m}$. The set of the two threads must be twisted to a minimum of 20 turns per meter. If the length is greater than $30 \mathrm{~m}$, it is preferable to connect the wire to the inductive-loop in the junction box with a return cable consisting of a pair of $2 * 1.5 \mathrm{~mm}^{2}$ braided at the rate of 10 slaps meter. The use of a shielded cable is only necessary in the case of several returns together within the same trench for more than $50 \mathrm{~m}$.

The Figure 3 shows the ditch where the coil should be installed. When a vehicle passes over the coil it generates some variation of parameters by the presence of a metal object, specifically the inductance of the inductive-loop, which is taken by the detectors found in the controllers and the system whose data it is compared to. Depending on the vehicular flow, it generates the most suitable time models for that crossing.

Inductance:

The inductance seen from the detector shall be between 20 and $700 u H$, depending on the sensitivity of the detector used. The normally used values are between 100 and $200 u H$.

Resistance:

The total resistance seen from the detector, including the power cord, will be less than $10 \Omega$. The type resistor is a 16 AWG caliber conductor in the order of $13.5 \Omega$ per $1000 \mathrm{~m}$.

Insulation:

The insulation in relation to earth, of the network of ties, shall be greater than $10 \mathrm{~m} \Omega$. 


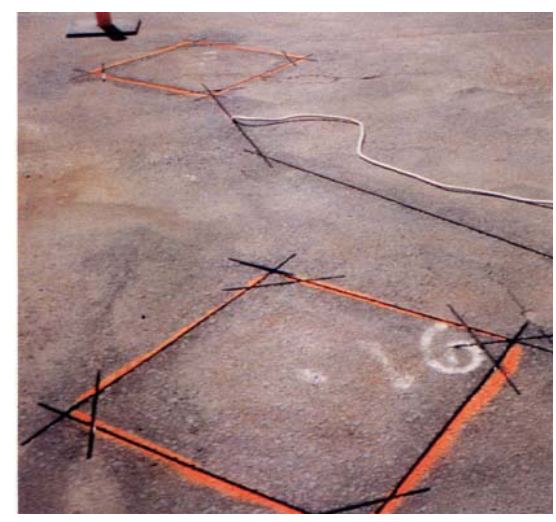

Figure 3. Inductive-loop traffic detectors traffic detectors.

\section{Geometry:}

The perimeter of the inductive-loop shall be between $3.5 \mathrm{~m}$ and $25 \mathrm{~m}$. Typical geometries are $2 m * 2 m$ inductive-loops; $2 m * 1.5 m ; 1.5 m * 1.5 m ; 2 m * 1 m$; etc. depending on the application.

If, for example, a $2.0 \mathrm{~m} * 2.0 \mathrm{~m}$ inductive-loop is used, the assembly of a tow vehicle shall be considered as a single vehicle. If a $2.0 m * 1.0 m$ inductive-loop is used, or narrower, this vehicle with ITS trailer can be seen as vehicles independent of each other.

The number of turns (or coils) of a single inductive-loop is a function of ITS perimeter in order to obtain an inductance value in the order of $100 \mathrm{uH}$ or higher [21]. A usable formula for calculating inductive-loop inductance is:

$$
L(u H)=3.28 * P(\text { perimeter in } \mathrm{m}) *\left(n^{2}+n\right) / 4
$$

Being $n=$ number of turns or coils.

However, if this model is applied for the use of vehicle step barriers located in the parking lots, it is strictly necessary that the installation of the coil be at least 1 meters, so that the metal object, either the barrier itself or a door, does not affect the reading of the sensor and produce sensing.

\subsection{Communication from the UOCT (Data Center)}

In this section we will look at the communication and structure of the equipment that exists in the $U O C T$ and that make it possible to control the traffic lights.

To begin with, Figure 4 shows the communication diagram of the traffic control system of the city of Santiago [22].

The diagram also shows the blocks that make up the entire system, highlighted in rectangles. By looking at the diagram, one can already deduce how computers interact, but it is completely necessary to investigate all components and communication protocol. To do this, the most important terms will be defined, which are set out in the diagram.

Communications digitizer:

This device digitizes the analog signals that are transmitted through telephone lines and that come from the ground, in order to be taken by communications PCs.

Communications PCs:

These teams are responsible for sending traffic control system information to traffic light controllers on the street. They transform data packets from traffic servers into messages that can be transmitted over similar telephone lines. Communication is at 1-second intervals to all traffic light controllers. Each PC communicates with a TCC server, so ITS denotation on the control system 


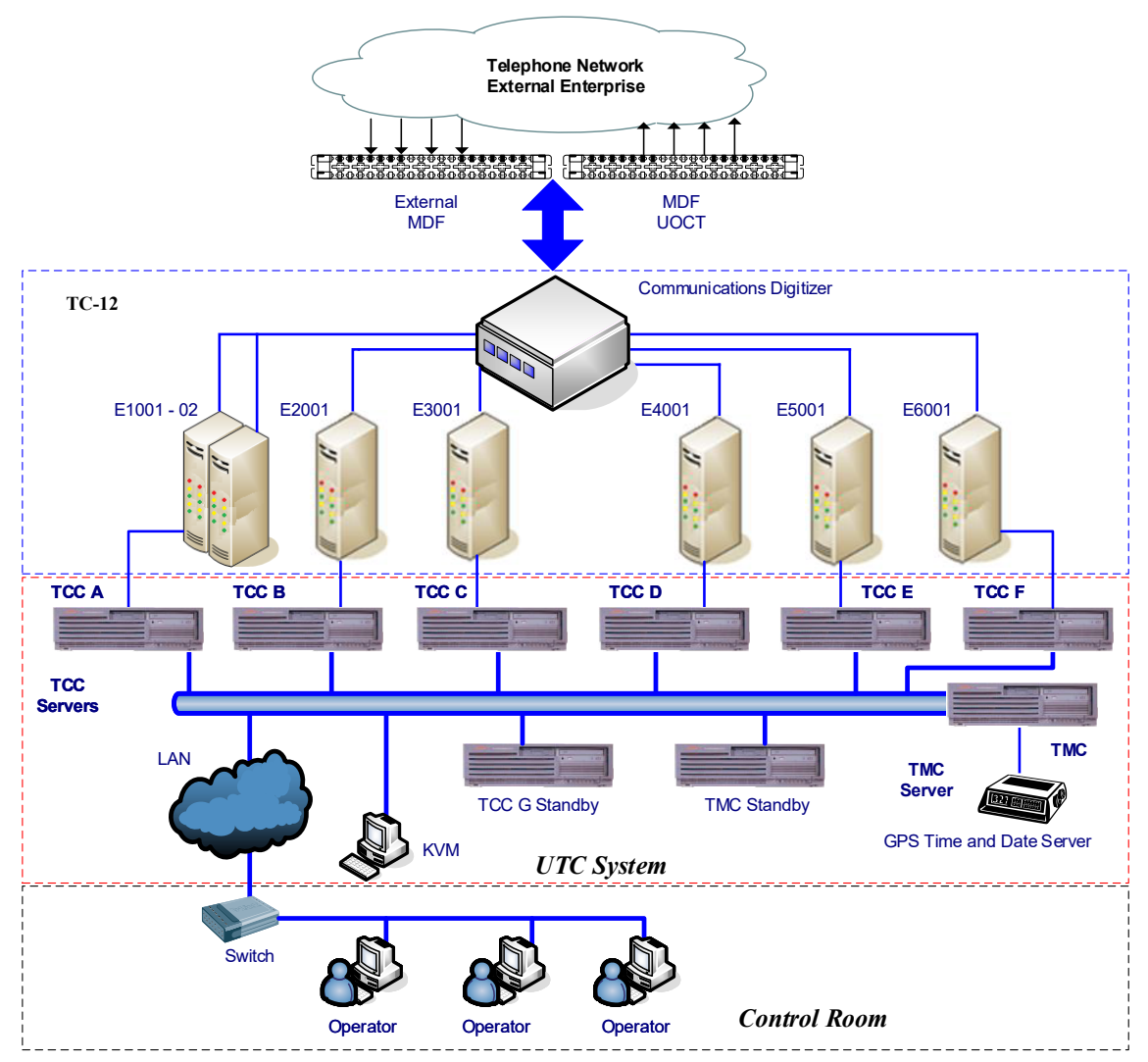

Figure 4. Proposed communication system UOCT Santiago.

is associated with it, so the TCCA server communications PC, is identified by E001001, and so on. Similarly, the PC associated with the TCCC will be identified as E003001 [23].

\section{Traffic Control Centre:}

There are 6 servers that are in charge of executing the different instructions and receiving responses from the different controllers in the field. They are called Traffic Control Computers [24]. These are labeled from A to F, and are assigned different areas of the Metropolitan region and grouped by behavior of the controller in the field, depending on plans, timetables, commune, etc.

\section{TMC primary server:}

The server network consists of a primary server called TMC [25] that contains a large database with all the information of the semaphorized intersections, but does not possess the ability to control traffic. Intersection information is transferred to other TCCs servers, which have a computer associated with them, called communications PC.

GPS:

This enables the keeping of the updated time of all systems associated with the Transit Control System of the city of Santiago.

Standby servers: These are two backup servers that can assume the connection of either TCC Traffic Control servers or TMC server. 
Operator Position:

It is presented by a graphical interface on the Windows platform called "Xvision", in which you can monitor the behavior of servers and controllers in the field, whether in SCOOT mode or in the execution of fixed plans, etc.

This entire system is called the "UTC System" (demarcated by the red and blue rectangle of Figure 4) where the term comes from the acronym of Urban Traffic Control [26]. This system is used for vehicle and pedestrian flow control in urban areas, all from a central computer system. This central system consists of TCC and TMC servers, and is programmed to execute the various plans that reach the ground towards the different intersections and their respective controllers [25].

Control data received by controllers causes operational changes as required by the intersection (as described in the first part) such as moving from UTC mode to a stage defined by the same field team such as CFL mode. After you have implemented the mode, the controller sends a response which is analyzed by the central computer. It should also be noted that it is through this system that the plan changes are made or a plan is executed in SCOOT (the response when implementing a SCOOT plan varies depending on the traffic conditions, and id detected by coils integrated into the pavement. The collected data are taken by different devices, either for the study of flow behavior or by statistics).

\section{Discussion}

The proposed system updated the ITS in Chile, which changed the infrastructure from analog to digital signal. This change enhanced the traffic monitoring in Chile to identify traffic jams, critical points, and synchronization problems [13]. However, this system does not integrate the last advances in ITS in Chile, such as the GPS in Santiago's Transport System to optimize the traffic [4]. Furthermore, a new version of this system should include new technologies such as big data [27], visible light communication [28], and autonomous vehicles [29] to improve the traffic flow. The proposed system can integrate the data to work with these technologies. Still, the government should invest in infrastructure to centralize the data, process the current state of roads, synchronize the traffic lights to diminish traffic jams and accidents.

\section{Conclusions}

In conclusion and in order to be able to properly introduce ITS technologies into transport systems in our country, it is necessary to follow the following steps:

Create ITS Chile as a collaborative organization that integrates public and private sector interests. This same organization should be responsible for advancing the generation of an ITS architecture for Chile, in channeling exchange programs with similar organizations of the developed world and other aspects of common interest. International experience should be incorporated into this creation, both in the definition of the roles assumed by national organizations and in the forms of funding.

Start a training program for young professionals in the field of ITS, taking advantage of the various opportunities offered in the developed world.

Organize technical visits aimed at learning from specific projects that use ITS technologies, selecting applications that give you priority in our country.

Complete a diagnosis of priority topics that justify ITS applications in Chile in various fields. For example, a strong need for ITS should be expected in the field of public transport management, the product of the implementation of a new policy of urban transport and public transport in the city of Santiago. New developments in transit management and support for commercial vehicles should also be expected from the UOCT as well as developments in rural roads, at border crossings, in ports and railways, as well as in transport management at the regional level.

Selected areas of greatest interest. An effort should be made to develop an ITS architecture for Chile in all of them, that facilitates the incorporation of technologies, that allows competition between suppliers and that allows integration and Interoperability. Although the American national 
architecture no doubt needs to be adapted to national reality, it seems to be a fairly flexible model to accommodate our country's own needs.

It is possible to think of initiatives such as developing one or more pilot projects in some of the areas mentioned above, obtaining partial funding from international agencies. Projects that reduce emissions, increase people's safety and/or reduce congestion, have more access to funding more quickly. In the view of this study, one of the areas that offers a high potential for profitability is in the regional area, with the capacity to replace large investment projects, essentially managing the demand of cargo transport that is growing due to new virtual services.

Develop a methodology or manual of evaluation of ITS projects for Chile, including from the identification of the project idea, preliminary evaluation and final evaluation.

The first two objectives generally receive the highest priority at an intersection. Of course, it is in the interest of meeting these objectives with a minimum cost in the traffic light system.

It is very important to adopt a rigorous methodology in the design of these intersections. A uniform methodology will allow the design of an intersection that meets the objectives mentioned above and at the same time ensures that the most relevant aspects have been taken into account.

Author Contributions: Conceptualization, Jorge Figueroa and Raúl Carrasco; Data curation, Raúl Carrasco and Diego Fuentealba; Formal analysis, Jorge Figueroa; Investigation, Jorge Figueroa, Raúl Carrasco, Diego Fuentealba, Eduardo Viera and Carolina Lagos; Methodology, Raúl Carrasco, Diego Fuentealba and Eduardo Viera; Project administration, Raúl Carrasco and Diego Fuentealba; Supervision, Raúl Carrasco; Validation, Diego Fuentealba; Visualization, Jorge Figueroa, Raúl Carrasco and Diego Fuentealba; Writing - original draft, Jorge Figueroa, Eduardo Viera and Carolina Lagos; Writing - review \& editing, Raúl Carrasco, Diego Fuentealba and Carolina Lagos.

Acknowledgments: The authors thank Paul Soper for the style correction of the language.

Conflicts of Interest: The authors declare that there is no conflict of interest in the publication of this paper.

\section{Abbreviations}

The following abbreviations are used in this manuscript:

$\begin{array}{ll}\text { CCTv } & \text { Closed Circuit Television } \\ \text { GIS } & \text { Geographic Information System } \\ \text { GPS } & \text { Global Positioning System } \\ \text { ITS } & \text { Intelligent Transport Systems } \\ \text { OTU } & \text { Outstation Transmission Unit } \\ \text { SCATS } & \text { Sydney Coordinated Adaptive Traffic System } \\ \text { SCOOT } & \text { Split Cycle Offset Optimisation Technique } \\ \text { TCC } & \text { Traffic Control Centre } \\ \text { TMC } & \text { Traffic Management Computer } \\ \text { UOCT } & \text { Operational Traffic Control Unit }\end{array}$

\section{References}

1. Centro de Computación (CEC). Conociendo el transporte: Gestión Integral de Tránsito, 2020.

2. Zaldívar-Colado, A.; Tripp-Barba, C.; Brito-Rojas, J.A.; Aguilar-Calderón, J.A.; García-Sánchez, O.V.; Ramírez-Zambada, L.; Zatarain-Montalvo, J.N. Reguliranje semafora u hitnim slučajevima. Tehnicki Vjesnik 2017, 24, 643-648. doi:10.17559/TV-20140910051747.

3. Salazar-Cabrera, R.; Cruz, Á.P.D.L.; Molina, J.M.M. Fleet Management and Control System from Intelligent Transportation Systems perspective. 2019 2nd Latin American Conference on Intelligent Transportation Systems (ITS LATAM); IEEE: Bogota, Colombia, 2019; pp. 1-7. doi:10.1109/ITSLATAM.2019.8721347.

4. Gschwender, A.; Munizaga, M.; Simonetti, C. Using smart card and GPS data for policy and planning: The case of Transantiago. Research in Transportation Economics 2016, 59, 242-249. doi:10.1016/j.retrec.2016.05.004.

5. Bello, O.; Zeadally, S. Toward efficient smartification of the Internet of Things (IoT) services. Future Generation Computer Systems 2019, 92, 663-673. doi:10.1016/j.future.2017.09.083. 
6. Chen, Y.; Ardila-Gomez, A.; Frame, G. Achieving energy savings by intelligent transportation systems investments in the context of smart cities. Transportation Research Part D: Transport and Environment 2017, 54, 381-396. doi:10.1016/j.trd.2017.06.008.

7. ITS Chile. Autopistas: El futuro de los ITS en Chile. Trayectos 2010, 12, 30-33.

8. Kyber. Análisis del estado del arte en tecnologías para el transporte y formulación de ideas de proyecto. Technical report, 2001.

9. Pérez, G. Telemática: Un nuevo escenario para el transporte automotor; Vol. 30, Recursos Naturales E Infraestructura, Cepal: Santiago, Chile, 2001; p. 79.

10. He, Z.; Zhang, L.; Zhang, H.; Liu, X. Integrated modeling and control of urban road traffic networks. Proceedings of 2017 IEEE 6th Data Driven Control and Learning Systems Conference, DDCLS 2017; IEEE: Chongqing, China, 2017; pp. 733-738. doi:10.1109/DDCLS.2017.8068164.

11. Suarez, M.; Esperanza Alvarez, L.; Camacho, P.; Marin, L.; Vasquez, B.; Gutierrez, G.; Aranzazu, R.; Carranza, M.; Montoya, F.; Valdes, A.; Gonzalez, C.; Jaramillo, M.; Henao, S. Dynamic Allocation of Traffic Light Plans as a Traffic Reduction Strategy. MOVICI-MOYCOT 2018: Joint Conference for Urban Mobility in the Smart City; Institution of Engineering and Technology: Medellin, Colombia, 2018; pp. 1-7. doi:10.1049/ic.2018.0012.

12. Ministerio de Justicia. Ley 18290, Ley de transito, 2009.

13. Tekia Ingenieros. Diagnóstico Sistemas de Control de Tránsito del País. Technical report, Ministerio de Transportes y Telecomunicaciones, Santiago, Chile, 2017.

14. Siemens AG. Sitraffic C920ES Traffic Controller Series: Maximum energy efficiency thanks to 1 Watt Technology. Technical report, Mobility Division Intelligent Traffic Systems, Siemens AG, Munich, Germany, 2016.

15. Přikryl, J. Simple model for urban traffic between two signalized intersections. I16th International IEEE Conference on Intelligent Transportation Systems (ITSC 2013); IEEE: The Hague, Netherlands, 2013; pp. 41-46. doi:10.1109/ITSC.2013.6728208.

16. Bretherton, D.; Cowling, J.; Hay, G. Advice Leaflet 1: The " SCOOT " Urban Traffic Control System. Technical report, SCOOT Systems, Berks, UK, 2005.

17. Studer, L.; Ketabdari, M. Analysis of Adaptive Traffic Control Systems Design of a Decision Support System for Better Choices. Journal of Civil E Environmental Engineering 2015, 05. doi:10.4172/2165-784x.1000195.

18. Berndt, S.; Geißler, T.; Schulz, S.; Kühnel, C.; Alkim, T.; Jorna, R.; Narroway, S.; Wadsworth, P.; Kulmala, R.; Tarkiainen, M.; Svedlund, J.; Mainardi, P.; Magagnoli, F.; Frémont, G.; Dumitrescu, S.; Blanco, A. EIP + White Paper on Cooperative ITS Services. Technical report, European ITS Platform, 2016.

19. Unidad Operativa de Control de Transito de Santiago. Manual de comandos del sistema de control de tránsito. Technical report, Gobierno de Chile, Santiago, 2005.

20. Wang, L.; Pan, S.; Zhang, Y.; Li, Z. Urban traffic complex network hub node analysis and signal control optimization strategy research. 2010 Chinese Control and Decision Conference, CCDC 2010; IEEE: Xuzhou, China, 2010; pp. 4172-4175. doi:10.1109/CCDC.2010.5498407.

21. Middleton, D.; Parker, R. Initial Evaluation of Selected Detectors to Replace Inductive Loops on Freeways. Technical report, 2000.

22. Ltifi, A.; Zouinkhi, A.; Bouhlel, M. A Trust Management System Through Ambient Communication for VANET. International Journal of Informatics and Communication Technology (IJ-ICT) 2013, 2, 71-78. doi:10.11591/ij-ict.v2i2.2980.

23. Siemens Mobility. System Requirement Specification for an STC UTC System. Technical Report 30, Siemens, 2015.

24. Pickering, A. Siemens TC12 Installation, Commissioning and Maintenance Handbook. Technical Report 10, SIEMENS, 2004.

25. Pickering, A. TC12 General Handbook. Technical Report 8, Siemens plc, Poole, UK, 2002.

26. Harrison, M.E.J. SCOOT Traffic Handbook, SCOOT 0494, Glossary of Traffic Terms. Technical report, Siemens, 2000.

27. Zhu, L.; Yu, F.R.; Wang, Y.; Ning, B.; Tang, T. Big Data Analytics in Intelligent Transportation Systems: A Survey. IEEE Transactions on Intelligent Transportation Systems 2019, 20, 383-398. doi:10.1109/TITS.2018.2815678. 
28. Martinek, R.; Danys, L.; Jaros, R. Visible Light Communication System Based on Software Defined Radio: Performance Study of Intelligent Transportation and Indoor Applications. Electronics 2019, 8, 433. doi:10.3390/electronics8040433.

29. Jármai, K.; Bolló, B. Vehicle and Automotive Engineering. Lecture Notes in Mechanical Engineering; Jármai, K.; Bolló, B., Eds.; Springer International Publishing: Cham, 2017; Lecture Notes in Mechanical Engineering, pp. 287-307. doi:10.1007/978-3-319-51189-4. 